\begin{tabular}{ccc}
\hline & International Journal of Engineering \& Technology, $7(2.33)(2018) 588-590$ \\
SPC & International Journal of Engineering \& Technology \\
Website $:$ www.sciencepubco.com/index.php/IJET & Research paper \\
\hline
\end{tabular}

\title{
Service based collaborative framework for smart gardening
}

\author{
V. Kavitha ${ }^{1 *}$, Dr. P. Shanmugapriya ${ }^{2}$, A. S. Aisshwaryapriya ${ }^{3}$, M. Harini ${ }^{3}$ \\ ${ }^{1}$ Assoc. Prof, Department of Computer Science \& Engineering, Sri Sai Ram Engineering College, Research Scholar, SCSVMV Universi- \\ ty \\ ${ }^{2}$ Assoc. Prof, Department of Computer Science \& Engineering, SCSVMV University \\ ${ }^{3}$ Student, Department of Computer Science \& Engineering, Sri Sai Ram Engineering College, Chennai, Tamil Nadu, India \\ *Corresponding author E-mail: kavitha.cse@sairam.edu.in
}

\begin{abstract}
Service oriented architecture (SOA) is being an evolving technology, which allows various applications to talk with each other and share data and services through a provider, mediator and service requestor with a service description. This paper recommends a way for the development of "smart gardening" using web services in combination with internet of things (IoT). This approach helps to develop, deploy, integrate and manage various services through a collaborative framework for the effective maintenance of plant growth. The usage of IoT will help people to use the sophisticated techniques to improve the maintenance. IoT is used for sensing soil moisture and nutrients, controlling water usage for plant growth and determining custom fertilizer. Further, it also aims to maintain the environmental constancy and sustainability.
\end{abstract}

Keywords: Internet of Things; Services; Smart Gardening; SOA

\section{Introduction}

Green living has become widespread and many people are now interested in home gardening. The main reason that people rely on home gardening is they could produce organic food items for their own consumption and promote a sound state of health. However some people wish to grow ornamental plants for beauty. But a serious issue is that people don't have enough time to look after the garden in their busy schedule. Also people don't have adequate knowledge of how well is a garden to be maintained. In this approach we encompass a collection of web services under a single framework using service oriented architecture(SOA) to make web, a place of choice for the convenience of human activities and to address the various challenging issues.

A web service is a set of related functionalities that can be programmatically accessed and manipulated through the web. Web services provide a platform for exchanging information between devices over a network. Service oriented architecture is a way to approach the challenge of integrating application functions that run on different software platforms including applications on the same platform. Let us consider the following scenario: $\mathrm{X}$ (a person) wants to maintain a garden with variety of plants. Due to lack of time and proper guidance he approaches different service providers for each service like delivery of plants, maintenance, suggestions etc.. which is going to be expensive and time consuming. Instead X can make use of service oriented architecture which consists of all the services necessary to maintain a garden effectively and efficiently.

\section{Related work}

With the continuous increase in world's population, demand for food supply is extremely raised. Governments are helping farmers to use advanced technologies and increase the food production. So, many projects have been developed based on web services for gardening, agriculture etc. But it is based on the fact that each service is provided separately by different service providers. Service oriented architecture brings together all the services that people need. Here the services in SOA are independent of each other even though present under a single framework. Moreover many services has been developed on agricultural basis i.e. large scale implementation. This idea is ineffective when service consumers need services for a small area implementation and from a single service provider. Internet of things highlights on connecting objects which are surrounded us by leveraging a variety of wireless communication technologies. The IoT allows you to automate and control the tasks that are done on a daily basis, avoiding human intervention. So combining service oriented architecture along with IOT enhances the development and maintenance of the system. Therefore our approach provides a better solution to deal with the issues stated above.

\section{Overview of framework}

In our approach we have provided a better solution to rise above the problems and challenges that people face while setting up and maintaining the garden. We have brought together a collection of web services under a single architecture to perform "Smart Gardening".

\subsection{System architecture $\&$ implementation}

The system architecture shows a number of web services enclosed under a single framework. These services include: Delivery of plants or seeds according to the desire of the consumers. Initial setup includes preparing and deploying suitable environment according to the plant types, choosing the right plants for your 
space. Maintenance of plants include giving intimation to the consumer like watering of plants at proper time, adding of fertilizer when necessary, maintaining healthy moisture soil levels, providing guaranteed plant care services on a weekly basis etc. Harvest stage includes giving proper guidance like when to harvest the vegetables and steps to be followed prior to harvest and so on.

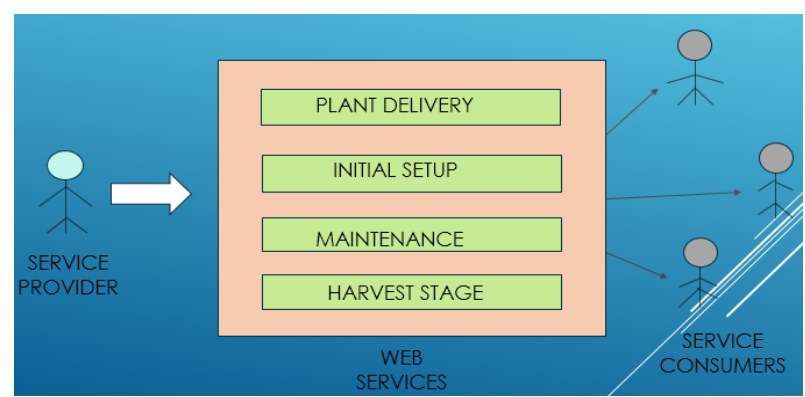

Fig. 1: System Architectue.

The intimation to the consumer is given to his/her smart phone. This is going to be achieved by connecting a 5 -wired sensor in a plant and connecting it in series to a few more plants. The first wire is for maintaining the signal voltage. The $2^{\text {nd }}$ wire isolates the ground in order to decrease signal noise. 3rd and 4th wires are for heating an element so that the sensor which is in plant starts operating quicker and reliably. 5th wire detects the measurements by how much rich or lean they are. Here we make use of moisture sensor and mineral sensor. The former is used to check the moisture level in the soil and the latter is used to detect the different mineral content in the soil. To transmit the message from sensor to a device we make use of microcontroller which detects the measurements from sensor and passes it to the mobile phone. In this case message will be transmitted in a wireless network.

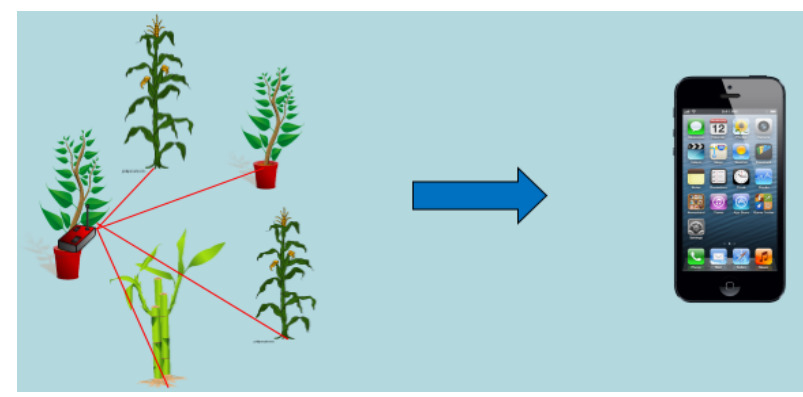

Fig. 2: IoT Integration.

The moisture sensor and mineral sensor is fitted into the soil. Both the sensors are supplied with a 5volt power supply. The measurements from the sensor ia passed as a signal to the microcontroller. An electric pump is also connected with the microcontroller which gives on/off signal to the electric pump to make the sprinkler system work. The electric pump is supplied with 220 volt AC power supply. The microcontroller detects the level of nutrients and sends the intimation to the service consumer through an SMS via a mobile network.

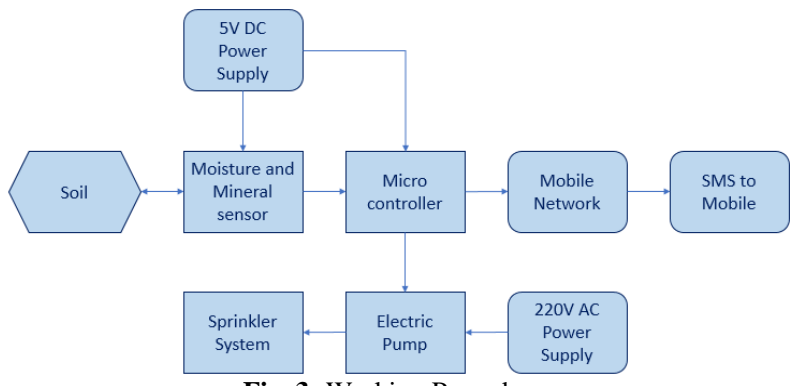

Fig. 3: Working Procedure.

\section{Results}

Here we provide a number of web services enclosed under a single framework.

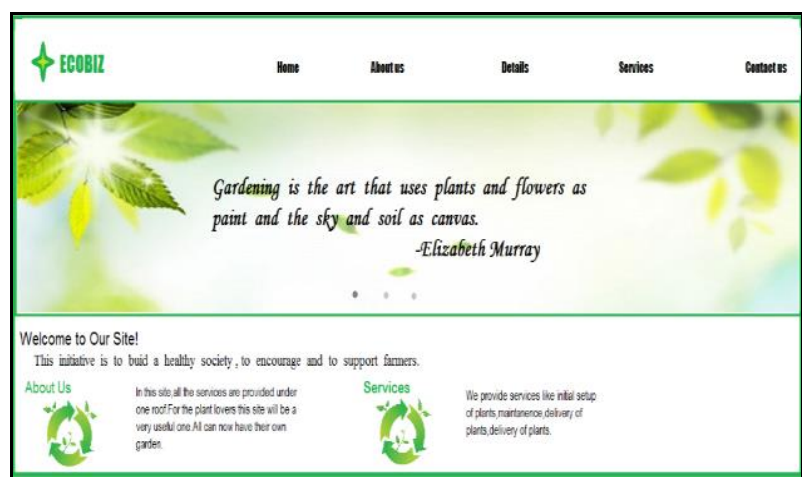

Fig. 4: Frame Work Home Page.

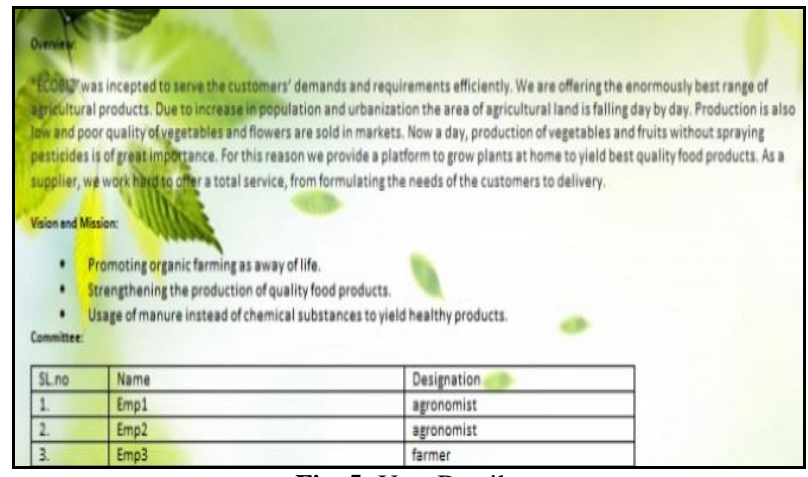

Fig. 5: User Details.

The below figure presents different services like plant delivery, initial setup, maintenance, suggestions and harvesting period. Initially plant is delivered, ideas are given regarding initial setup, maintenance of plants is done using sensors, suggestions are given regarding plant selection and harvesting period

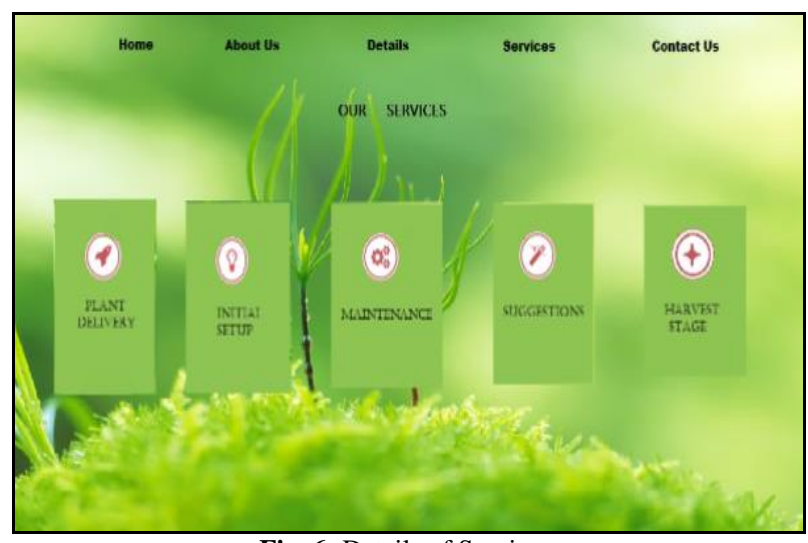

Fig. 6: Details of Services.

The below figure classifies plants into different categories like pharmaceutical plants, ornamental plants and vegetable plants. Each category consists of several plants in it. The website consists of plant details along with the image of the plant so that it will be easy for the customer to choose the type of plant that he/she requires. The details consists of plant name, the suitable climatic condition the plant grows, the cost of the plant etc..After the customer chooses the plant to buy he can submit the details ,make payment and buy that plant. 


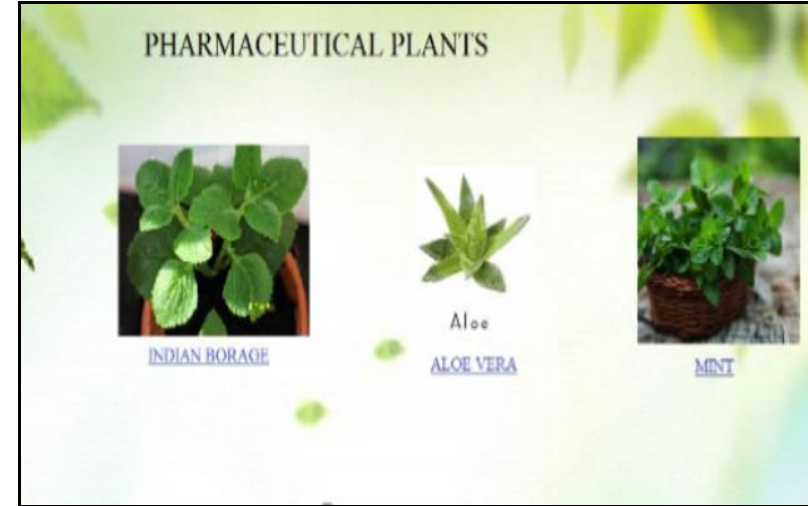

Fig. 7: Plants - Pharmacetical.

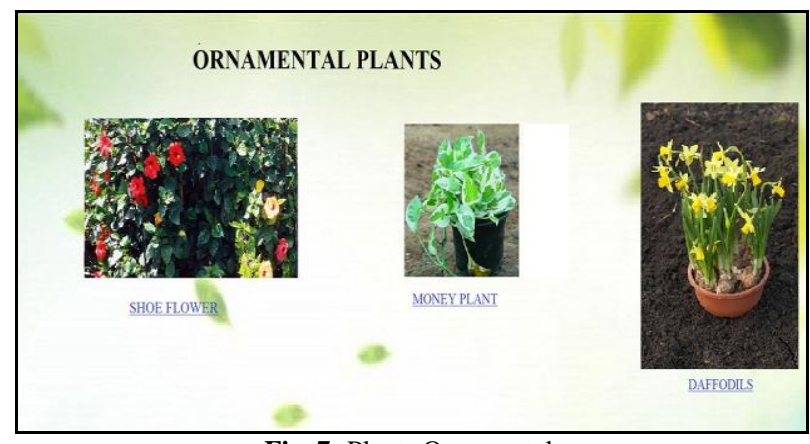

Fig. 7: Plants Ornamental.

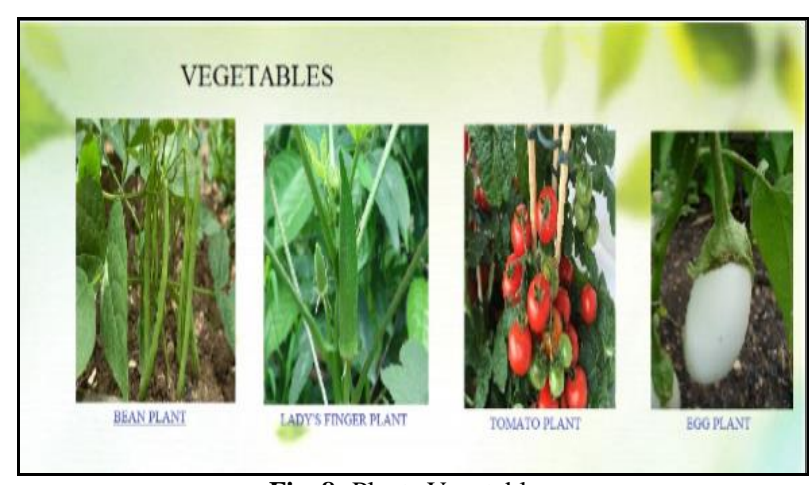

Fig. 8: Plants Vegetables.

The below specified form is used for registration and requesting and of the above mentioned service .

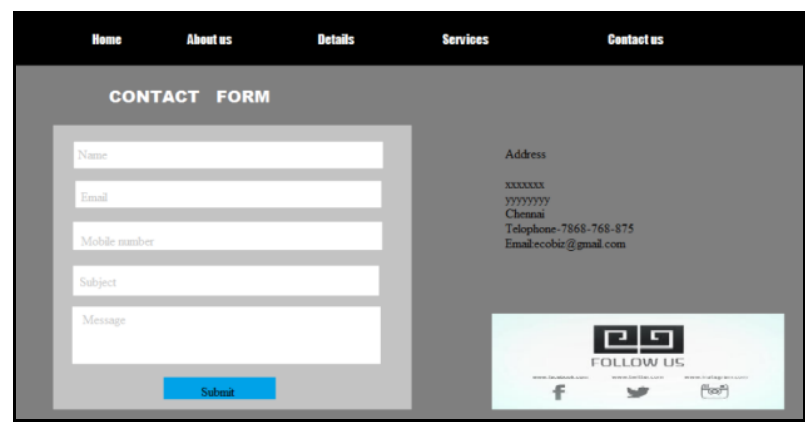

Fig. 9: Requisition for Service.

\section{Conclusion}

Smart gardening provides people with interoperable e-services that improve their quality of life while fulfilling the environmental sustainable responsibilities. People can be self-dependent in producing their own organic food items of high quality that promotes longer healthier life. People can also grow different variety of plants especially vegetable plants, pharmaceutical plants which will be very helpful for their consumption. Moreover people need not search for different service providers for each service they require for the proper growth of plants. Thus the framework that has been proposed in this paper can be used as a foundation to build a healthy environment.

\section{References}

[1] Hisham Elhoseny,Mohamed Elhoseny,Hazem E El -Bakry,Alaa Eldin Mohamed Riyad,'Utilizing service oriented architecture in smart cities",International journal of advancements in computing technology(June 2016)

[2] Mr.Dinesh Patil,Prof.Umesh Lilhore,"Study of SOA and mashup technique for handling confidentiality of private data" ,International Journal of research in advent technology vol.4,No.3,(March 2016).

[3] Gregoris Mentzas, ET. Al, "A collaborative decision framework for managing changes in e-Government services", Science Direct, Government Information Quarterly, pp. 101-116, 2010.

[4] Xumin Liu, et.al, "Efficient change management in long-term composed services", Original Research Paper, Springer-Verlag, 2010.

[5] Rolim, C.Rosseto, A.Leithardt, V.Borges, D.Dos santos, T.Souza, A.Geyer,"An Ubiquitos service oriented architecture for urban sensing.Agent technology for intelligent mobile services and society" Vol.498.pp.1.10.2015.

[6] Prandi, F.Soave, M.Devigili, F.Andreolli , M.De Amisis,'Service oriented smart city platform based on 3D city model visualization".ISPRS. Annals of the photo grammatry, Remote sensing and spatial information sciences.Vol.2.No.4.2014. 